\title{
Study on Effects of Cutting Fluids on Cutting Resistance and Tool Wear in Simple Method for Incoloy 825 Reaming
}

\author{
Rikio Hikiji ${ }^{\mathrm{a}, *}$ \\ ${ }^{a}$ Kumamoto University, 2-40-1 Kurokami, Chuo-ku, Kumamoto 860-8555, Japan \\ *Corresponding Author: hikiji@educ.kumamoto-u.ac.jp
}

\begin{abstract}
The reaming deals with cutting and burnishing simultaneously and needs a severe cutting performance. The cutting mechanism is so complicated that the method of evaluating the effects of the cutting fluids on the finished surface integrity and the tool life is not easy. In this study, the examination was carried out to extract an optimum cutting fluid in Incoloy 825 reaming. That is, instead of reaming, the simple method was established to experimentally investigate the effect of the cutting fluids on the cutting resistance and tool wear. This method is applicable to reaming processes supported by devising the tool geometry and the cutting conditions in facing with the $\mathrm{CNC}$ lathe. As a result, it was clarified that the synthetic soluble showed good performance for the cutting resistance and tool wear and this simple method was effective for the evaluation of the optimum cutting fluids in Incoloy 825 reaming.
\end{abstract}

Keywords: reaming, Incoloy 825, cutting fluid, cutting resistance, tool wear.

\section{Introduction}

Nickel-based super alloys can keep high temperature strength in a very hot environment, so they are used as part of gas turbines for the power plant and the aircraft engine. On the other hand, super alloys are classified as difficult-to-cut materials ${ }^{(1)}$. Some researches of the tool wear for Inconel 718 machining, which is one of typical super alloys, have been investigated ${ }^{(2-4)}$. In order to conserve the global environment, the research and development of minimal quantity lubrication (MQL) ${ }^{(5)}$ and dry machining ${ }^{(6)}$ have been investigated. As for reaming, because it is not easy to carry out dry machining due to the requirement of burnishing, it is necessary to supply the cutting fluids to the cutting point enough. The cutting fluids aiming at the balance of productivity and environmental conservation should be treated under the present conditions. However, it is difficult to examine the cutting fluids by using actual reaming due to several problems, such as a certain approach of cutting fluids to cutting edges and the deviation of the hole position between prepared hole drilling and reaming due to the tool exchange. This study suggests a simple method which can evaluate the optimum cutting fluids and support various machining processes by using a certain machining method. That is, this method is applicable to reaming processes supported by devising the tool geometry and the cutting conditions in facing with the CNC lathe. The previous study showed that this method was effective by using aluminum alloy ${ }^{(7)}$. In this study, the simple method was applied to Incoloy 825 , which is classified as a difficult-to-cut material due to low thermal conductivity, work hardening tendency, and its availability was investigated through the effect of the cutting fluids on the cutting resistance and tool wear.

\section{Simple Method}

In order to analyze the complicated reaming mechanism, some modeling tests of reaming have been suggested ${ }^{(8,9)}$. However, some problems between the modeling test and reaming occurred because of the deflection and chatter of the tool. Figure 1(a) shows the schematic of the experimental set up for extracting the optimum cutting fluids. The workpiece was attached to the chuck of the lathe and facing was carried out by sending the tool from the circumference to the center of this workpiece. Because the previous paper examined with the general-purpose lathe ${ }^{(10)}$ cutting speed has changed 


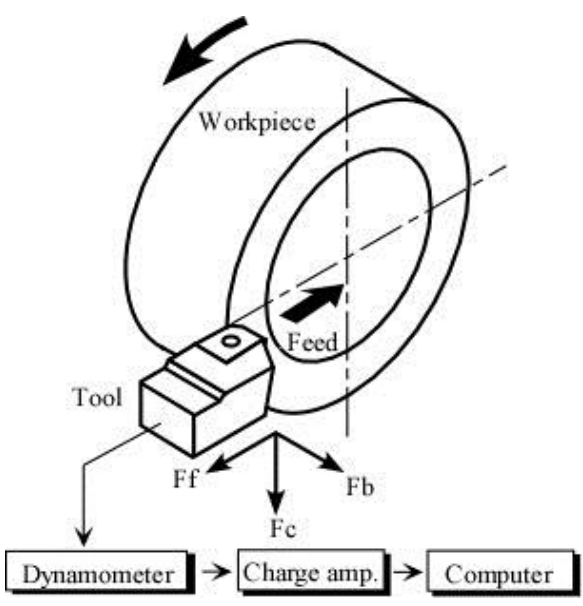

(a) Schematic of experimental set up.

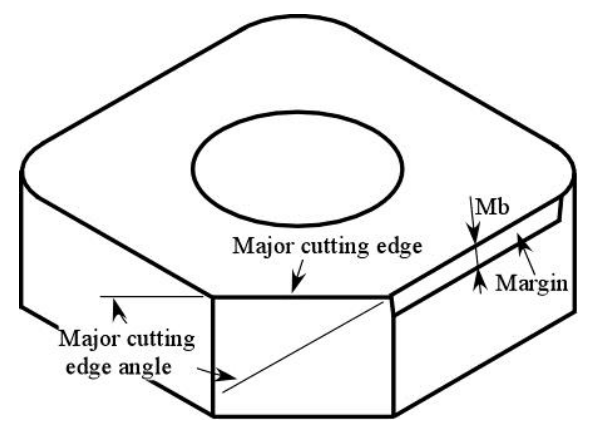

(b) Tool geometry of ground throw-away insert SNGA.

Fig. 1. Cutting method.

Table 1. Cutting conditions.

\begin{tabular}{|c|c|c|}
\hline Test & Reaming & Simple method \\
\hline Workpiece & \multicolumn{2}{|c|}{ Incoloy 825} \\
\hline Tool & $\begin{array}{c}\text { Carbide K10, Straight tooth } \\
\text { Diameter: } \varphi 10.0 \mathrm{~mm}, \quad \text { Number of flutes: } 6 \\
\text { Margin width: } 0.3 \mathrm{~mm} \\
\text { Chamfer angle: } 30 \mathrm{deg} . \\
\text { Back taper: } 0.03 / 100\end{array}$ & $\begin{array}{l}\text { Carbide K10, SNGA120404 } \\
\text { Margin width: } 0,0.3,0.6 \mathrm{~mm} \\
\text { Major cutting edge angle: } 30 \mathrm{deg} \text {. } \\
\text { Rake angle: }-6 \mathrm{deg} . \\
\text { Clearance angle: } 6 \mathrm{deg} .\end{array}$ \\
\hline Depth of cut a [mm] & $\varphi 0.2$ (corresponding to removal amount) & 0.1 \\
\hline Cutting speed $V \quad[\mathrm{~m} / \mathrm{min}]$ & \multicolumn{2}{|c|}{10} \\
\hline Feed rate $\mathrm{f} \quad[\mathrm{mm} / \mathrm{rev}]$ & \multicolumn{2}{|c|}{0.1} \\
\hline
\end{tabular}

gradually at the cutting position between the circumference to the center. In this study, the constant surface speed control mode was used with the $\mathrm{CNC}$ lathe in order to prevent the influence of the change of the cutting speed. The tool geometry is very important in this experiment and corresponds to every machining style. This study aimed to reproduce burnishing function with the cutting edge, and the tool geometry was shaped as shown in Fig.1(b). In other words, the section part of negative square cemented carbide throw-away insert SNGA was ground, the chamfer corresponding to the reamer was made. The major cutting edge angle of this insert corresponds to the chamfer angle of the reamer. And the minor cutting edge angle corresponds to the back taper. The margin width $\mathrm{Mb}$ which affects burnishing function was shaped with the cutting edge by grinding. This insert was put on the tool holder and the holder was attached by corresponding to the back taper of an actual reamer.

\section{Experimental}

\subsection{Work Material}

In this experiment, Incoloy 825 was used as a specimen. Incoloy 825 is a nickel iron chromium alloy with additions of molybdenum, copper and titanium, with exceptional resistance to many aggressive corrosion environments ${ }^{(11)}$. The chemical composition is $42.0 \% \mathrm{Ni}, 21.5 \% \mathrm{Cr}, 2.2 \%$ Mo, $2.2 \% \mathrm{Cu}, 0.9 \% \mathrm{Ti}$ and balance Fe. This alloy has good impact strength at room temperature, and retains its strength at cryogenic temperatures. It is used for chemical processing, pollution-control equipment, oil and gas well piping, nuclear fuel reprocessing, acid production, and pickling equipment. In addition, this alloy is classified as a difficult-to-cut material due to low thermal conductivity, work hardening tendency, and strong tendency of welding and adhesion of work material onto the cutting tool.

\subsection{Experimental Conditions}

As for the actual reaming, the experiment was carried out by using the vertical machining center Dura Vertical 5060 made by Mori Seiki. Center drilling, prepared hole 
Table 2. Cutting fluids.

\begin{tabular}{|c|c|c|c|c|c|}
\hline Label & Mist & Em & SE & SS & Oil \\
\hline Type & Polyol ester & Emulsion & Synthetic emulsion & Synthetic soluble & $\begin{array}{c}\text { Water-immiscible } \\
\text { cutting fluid }\end{array}$ \\
\hline Density $\left[\mathrm{g} / \mathrm{cm}^{3}\left(15^{\circ} \mathrm{C}\right)\right]$ & 0.95 & 0.938 & 1.07 & 0.99 & 0.86 \\
\hline $\begin{array}{c}\text { Surface tension } \\
{\left[\mathrm{mN} / \mathrm{m}\left(25^{\circ} \mathrm{C}\right)\right]}\end{array}$ & - & 34 & 30.1 & - & - \\
\hline $\begin{array}{c}\text { Kinematic viscosity } \\
{\left[\mathrm{mm}^{2} / \mathrm{s}\left(40^{\circ} \mathrm{C}\right)\right]}\end{array}$ & 19.1 & - & - & - & 15.0 \\
\hline $\mathrm{S}($ Sulfur $)$ & - & $\circ$ & $\circ$ & - & 0 \\
\hline Blow pressure $[\mathrm{MPa}]$ & 0.5 & - & - & 10 & - \\
\hline Flow rate $[\mathrm{L} / \mathrm{min}]$ & $10^{-2}$ & 10 & & 10 \\
\hline
\end{tabular}

drilling and finish reaming were performed by a series of program operations. Concrete cutting conditions are shown in Table 1. The plate specimens of Incoloy 825 with a thickness of $18 \mathrm{~mm}$ were used for the reaming test. The tool material is cemented carbide $\mathrm{K} 10$, and has an allowable tolerance of $+0.004 \mathrm{~mm}$. The reaming torque and thrust were measured with Kistler multicomponent dynamometer type 9272 during reaming. After reaming, the width of the nose wear as the tool wear was measured with an optical microscope.

As for a simple modeling test, the experiment was carried out by using the CNC lathe TAC 510 made by Takizawa. Pre-machining and facing were performed by the constant surface speed control mode as shown in Table 1. The pipe specimens of Incoloy 825 with an outer diameter of $100 \mathrm{~mm}$ and inner diameter of $64 \mathrm{~mm}$ were used for this method. The end face of workpiece was machined up to the pipe thickness of $18 \mathrm{~mm}$ from circumference to center as shown in Fig.1(a). The depth of cut, feed rate and rake angle were constant. The cutting resistance was measured with Kyowa strain-gauge dynamometer type TD-300KA during facing. After facing, the width of the nose wear as the tool wear was measured with an optical microscope.

In these experiments, as cutting fluids, the emulsion including sulfur type extreme pressure additive, synthetic emulsion including a sulfur type extreme pressure additive, synthetic soluble and water-immiscible cutting fluid including sulfur type extreme pressure additive were used. Each feature is shown in Table 2. In the case of the water-miscible type, what diluted each of the types 10 times was used as a cutting fluid. In the entire test, the cutting fluid was added to the cutting point at the rate of $101 / \mathrm{min}$ with the external nozzle. In order to compare these setting fluids, MQL machining and dry machining were applied, too. As for MQL, polyol ester was supplied under 0.5 $\mathrm{MPa}$ blowing pressure and $10 \mathrm{ml} / \mathrm{min}$ flow rate.

\section{Results and Discussion}

\subsection{Cutting Resistance}

Figure 2 shows the change of the cutting resistance at $10 \mathrm{~m} / \mathrm{min}$ cutting speed. The figure (a) is the reaming and the figure (b) is the simple modeling test, respectively. The torque and the thrust of reaming correspond to the cutting force $\mathrm{Fc}$ and the feed force Ff, respectively. Furthermore, this modeling test has the vertical power (thrust force $\mathrm{Fb}$ ) acting on the finished surface, too. The thrust force $\mathrm{Fb}$ is the most important factor affecting burnishing and tool wear. In the case of a reamer with plural cutting edges, it is difficult to measure this force $\mathrm{Fb}$ for every cutting edge. Detecting the thrust force $\mathrm{Fb}$ is one of the features of this method.

As shown in Fig.2(a), the torque of reaming is divided into a cutting part and burnishing part like the previous $\operatorname{paper}^{(7,12)}$. An effective burnishing action leads to excellent finished surface integrity. The thrust has a cutting part and burnishing part, too. As shown in Fig.2(b), both component forces increase rapidly as soon as a cutting edge starts machining, and becomes gradually before long. The first rapid increase means a cutting and subsequent increase means burnishing by the finishing edge. The difference in burnishing is remarkable and the thrust force $\mathrm{Fb}$ is the largest in three component forces of the cutting resistance. 


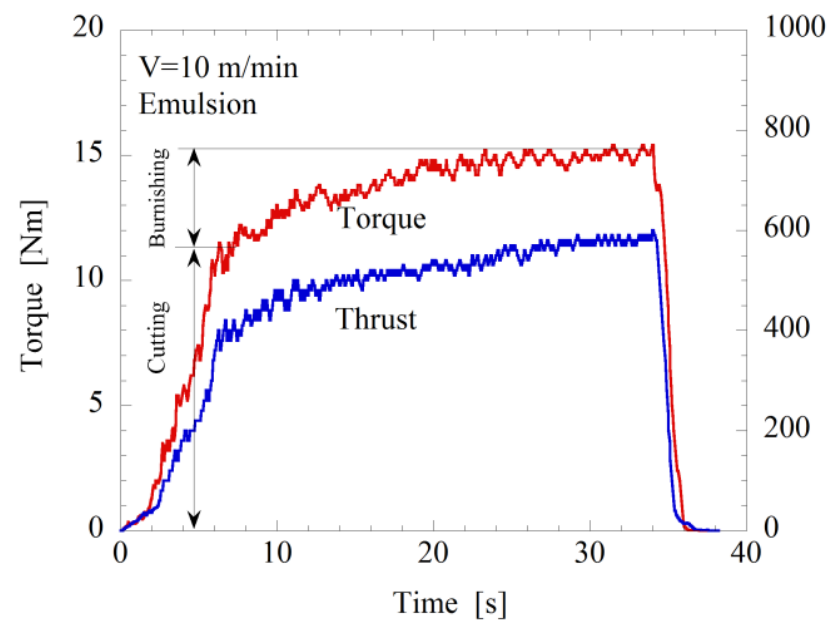

(a) Reaming.

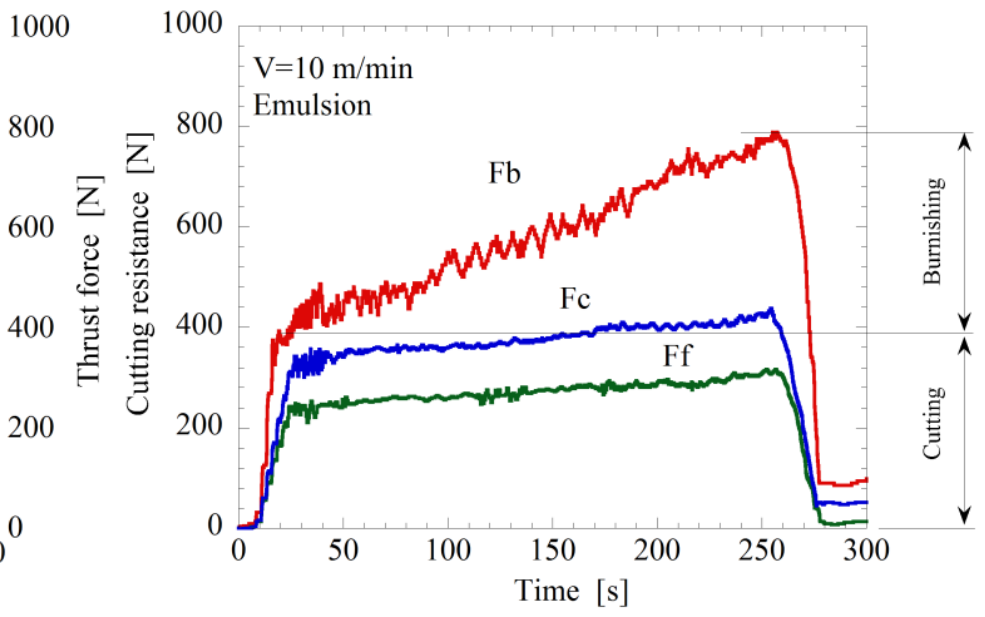

(b) Simple modeling test.

Fig. 2. Change of cutting resistance.

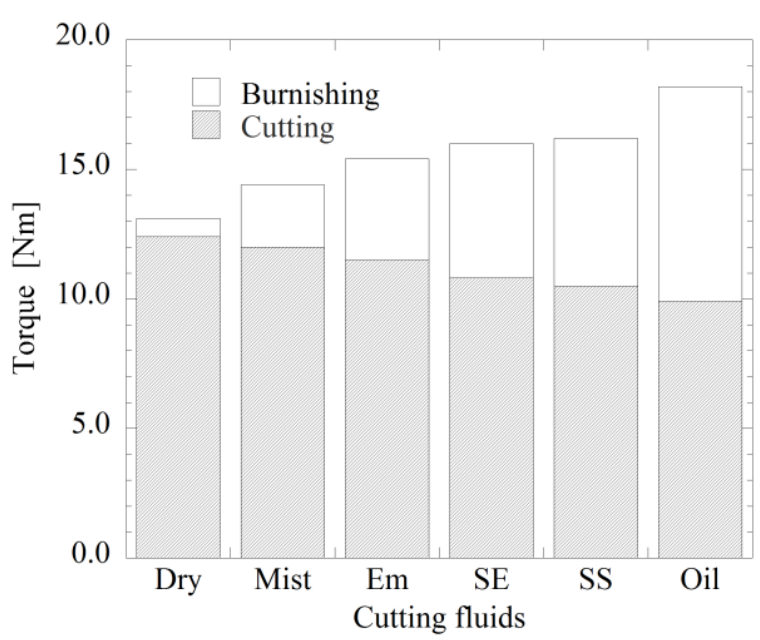

(a) Reaming.

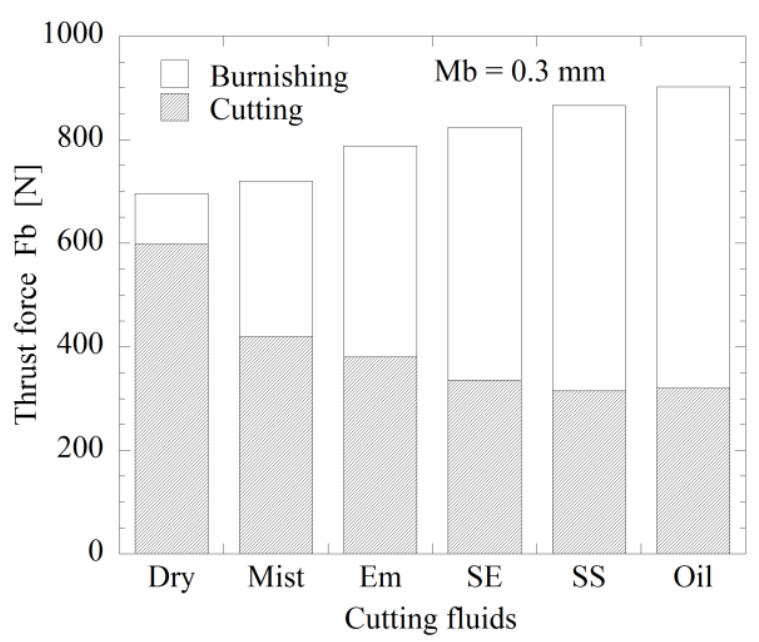

(b) Simple modeling test.

Fig. 3. Effects of cutting fluids on cutting resistance.

Figure 3 shows the effects of the cutting fluids on the cutting resistance. The figure (a) is the torque in reaming and the figure (b) is the thrust force $\mathrm{Fb}$ in the simple modeling test. Both the reaming and the simple modeling test show a similar tendency generally. In other words, the dry machining has a small cutting resistance, while the water-miscible and water-immiscible cutting fluids have a large one. Because the built-up edge (BUE) was piled upon the cutting edge in the case of dry machining, the cutting resistance decreased. The burnishing part, especially, shows a more remarkable change than the cutting part. As for the resistance of the cutting part, the good lubricity cutting fluids become small in cutting resistance. As for the resistance of the burnishing part, the case of the water-immiscible cutting fluid indicates large resistance because of the effective performance of good lubricity in the contact area between the margin of tool and finished surface. The thrust force $\mathrm{Fb}$ which cannot be evaluated directly from the torque and thrust in reaming becomes large in the case of good lubricity cutting fluids. This performance leads to the burnishing dominant factor.

\subsection{Tool Wear}

Figure 4 shows the effects of the cutting fluids on the corner wear $\mathrm{VC}$, in the case of margin width $\mathrm{Mb}=0.3 \mathrm{~mm}$. The figure (a) and the figure (b) show the case of the reaming and that of the simple modeling test, respectively. As shown in both figures, the more the cutting length increases, the more the corner wear $\mathrm{VC}$ increases. In the case of dry machining, the tool life becomes very short. On the other hand, in the case of water-miscible and immiscible cutting fluids, the tool life becomes longer relatively. Especially, the synthetic soluble which has high permeability shows good performance like the water-immiscible cutting fluid. From these results, the more the torque of the reaming or the thrust force of the 


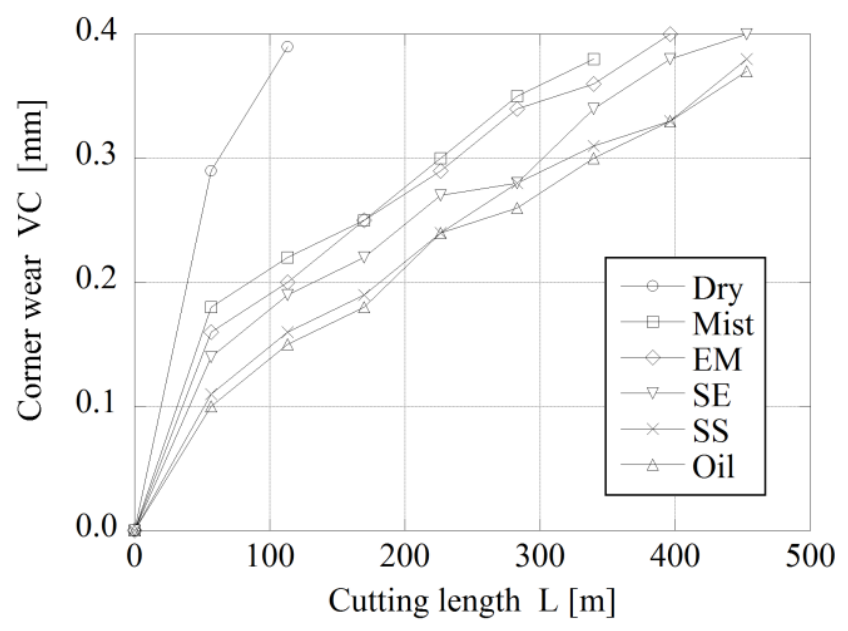

(a) Reaming.

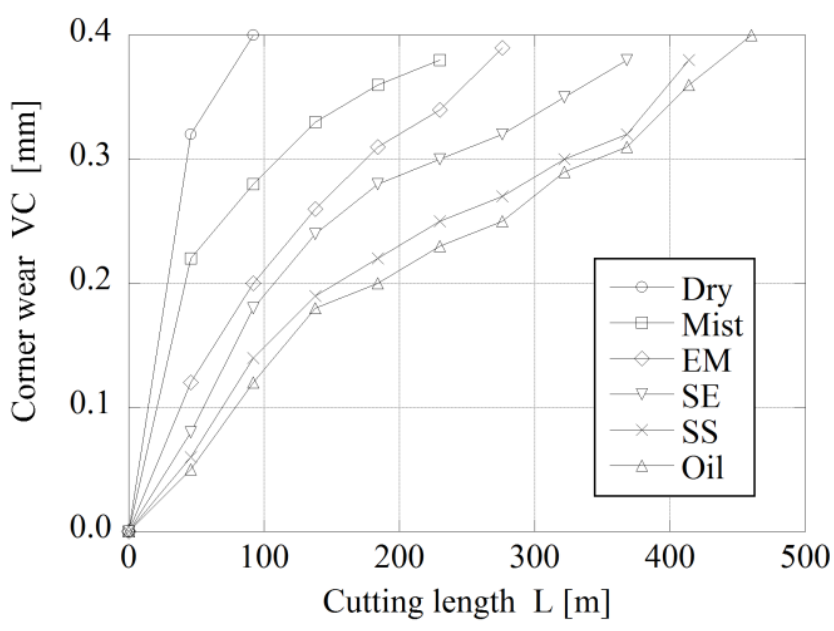

(b) Simple modeling test.

Fig. 4. Effects of the cutting fluids on corner wear $\mathrm{VC}$, in the case of margin width $\mathrm{Mb}=0.3 \mathrm{~mm}$.

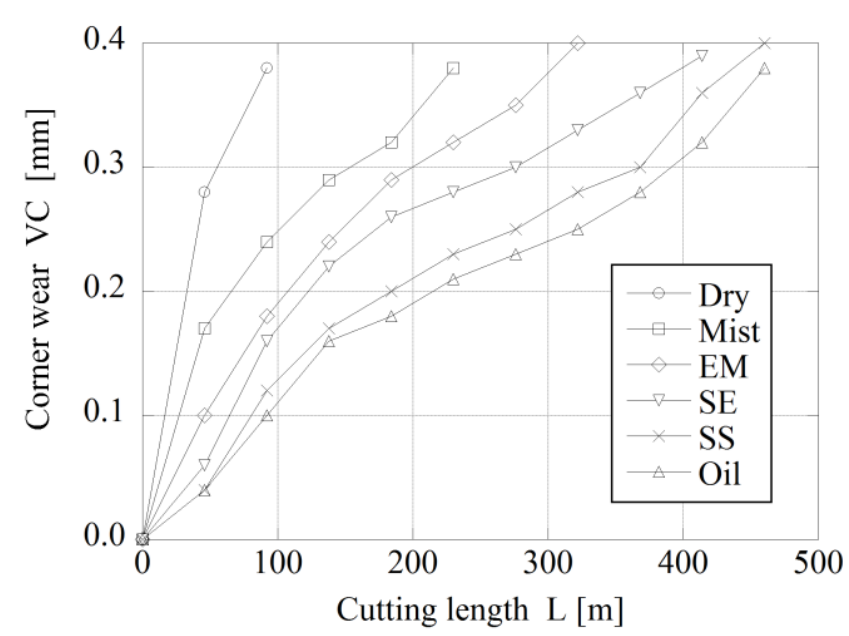

(a) $\mathrm{Mb}=0 \mathrm{~mm}$.

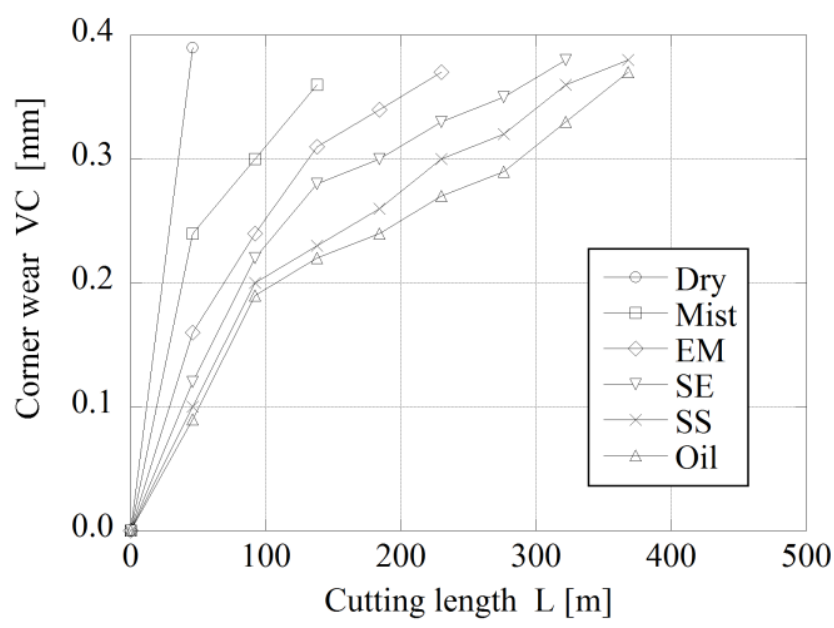

(b) $\mathrm{Mb}=0.6 \mathrm{~mm}$.

Fig. 5. Effects of margin width $\mathrm{Mb}$ and cutting fluids on corner wear $\mathrm{VC}$ in the case of simple modeling test.

simple modeling test increases, the more the tool life extends.

Figure 5 shows the effects of the margin width $\mathrm{Mb}$ and the cutting fluids on the corner wear $\mathrm{VC}$ in the case of the simple modeling test. The figure (a) and the figure (b) show the case of $\mathrm{Mb}=0 \mathrm{~mm}$ and that of $\mathrm{Mb}=0.6 \mathrm{~mm}$, respectively. From these figures, it is found that the corner wear $\mathrm{VC}$ at $\mathrm{Mb}=0.6 \mathrm{~mm}$ is larger than at $\mathrm{Mb}=0 \mathrm{~mm}$ in the same cutting length. In other words, burnishing action needs the margin width, but its width must not be too large.

Moreover, these figures show that in the case of the water-miscible and immiscible cutting fluids, the tool life becomes longer, compared with dry machining. In the case of the synthetic soluble, especially, it becomes extremely long. Therefore, it is necessary to put the margin width on the cutting edge, but larger width may make the tool wear inferior. As a result, the simple modeling test can be applied to prediction of the tool life for the actual reaming.

Now, it is necessary to consider these results by using the cutting resistance. Table 3 shows the Frictional coefficient from ratio between cutting force and thrust force in the case of the simple modeling test. In this table, Fc' is the burnishing component of the cutting force $\mathrm{Fc}$ and $\mathrm{Fb}^{\prime}$ is that of thrust force $\mathrm{Fb}$, respectively. From this table, it is found that the good lubricity cutting fluids have a small

Table 3. Frictional coefficient from ratio between cutting force and thrust force.

\begin{tabular}{|c|c|c|c|c|c|c|}
\hline Fluids & Dry & Mist & EM & SE & SS & Oil \\
\hline $\mathrm{Fc}^{\prime} / \mathrm{Fb}^{\prime}$ & 0.85 & 0.38 & 0.29 & 0.26 & 0.22 & 0.20 \\
\hline
\end{tabular}


frictional coefficient. Thus, these cutting fluids are effective to extend the tool life.

\section{Conclusions}

In order to extract an optimum cutting fluid in Incoloy 825 reaming, the availability of the simple method was investigated through the effects of cutting fluids on cutting resistance and tool wear, instead of the actual reaming.

As a result, it was clarified as follows:

(1) Incoloy 825 reaming can be modeled by facing with the CNC lathe.

(2) The good lubricity cutting fluids have a small frictional coefficient, and their burnishing action is remarkable. Therefore, they contribute to the extension of tool life.

(3) The long tool life was obtained in the case of the synthetic soluble as well as the water-immiscible cutting fluids.

(4) This method can be applied to other nickel based super alloys as well as Incoloy 825.

\section{References}

(1) A. Shokrani, V. Dhokia and S. T. Newman : "Environmentally conscious machining of difficult-to-machine materials with regard to cutting fluids", International Journal of Machine Tools \& Manufacture, Vol.57, pp. 83-101, 2012

(2) M. Rahman, W. K. H. Seah, and T. T. Teo : "The Machinability of Inconel 718”, Journal of Materials Processing Technology, Vol. 63, pp. 199-204, 1997

(3) H. Z. Li, H. Zeng, and X.Q. Chen : “An experimental study of tool wear and cutting force variation in the end milling of Inconel 718 with coated carbide inserts", Journal of Materials Processing Technology, Vol. 180, pp. 296-304, 2006

(4) E. O. Ezugwu, and J. Bonney : "Effect of high-pressure coolant supply when machining nickel-base, Inconel 718, alloy with coated carbide tools", Journal of Materials Processing Technology, Vol. 153-154, pp. 1045-1054, 2004

(5) Y. Kamata, and T. Obikawa : "High speed MQL finish-turning of Inconel 718 with different coated tools", Journal of Materials Processing Technology, Vol. 192-193, pp. 281-286, 2007

(6) A. Thakur, A. Mohanty, S. Gangopadhyay, and K. P. Maity : "Tool wear and chip characteristics during dry turning of cutting Inconel 825", Procedia Materials Science, Vol. 5, pp. 2169-2177, 2014

(7) R.Hikiji : "Study of Simple Modeling Test for Extraction of Optimum Cutting Fluids in Reaming", The Proceedings of the 2014 International Conference on Mechanical Design, Manufacture and Automation Engineering, pp.40-45, 2014

(8) K. Okushima, K. Hitomi, and S. Suzuki : "Fundamentals of Reaming Operation -Experimental Results on Boring Tests with Single-edged Cutting Tools Resembling Reamer Shape-", Journal of the Japan Society for Precision Engineering, Vol.29, No.8, pp.574-579, 1963

(9) K. Sakuma : "Influence of Cutting Fluids on Performance of Carbide Tools", Journal of japan Society of Lubrication Engineers, Vol.14, No.7, pp.383-390, 1969

(10) H. Ono, and M. Arai : "New Method for Estimating the Performance of Cutting Fluids", Journal of the Japan Society for Precision Engineering, Vol.27, No.3, pp.221-222, 1993

(11) Special metals : "Product Handbook of High-Performance Alloys", Special Metals Corporation, p. 19,2008

(12)L. V. Colwell and H. Branders : "Behavior of Cutting Fluids in Reaming Steels", Transactions of the American Society of Mechanical Engineers, Vol.80, pp.1073-1078, 1958 